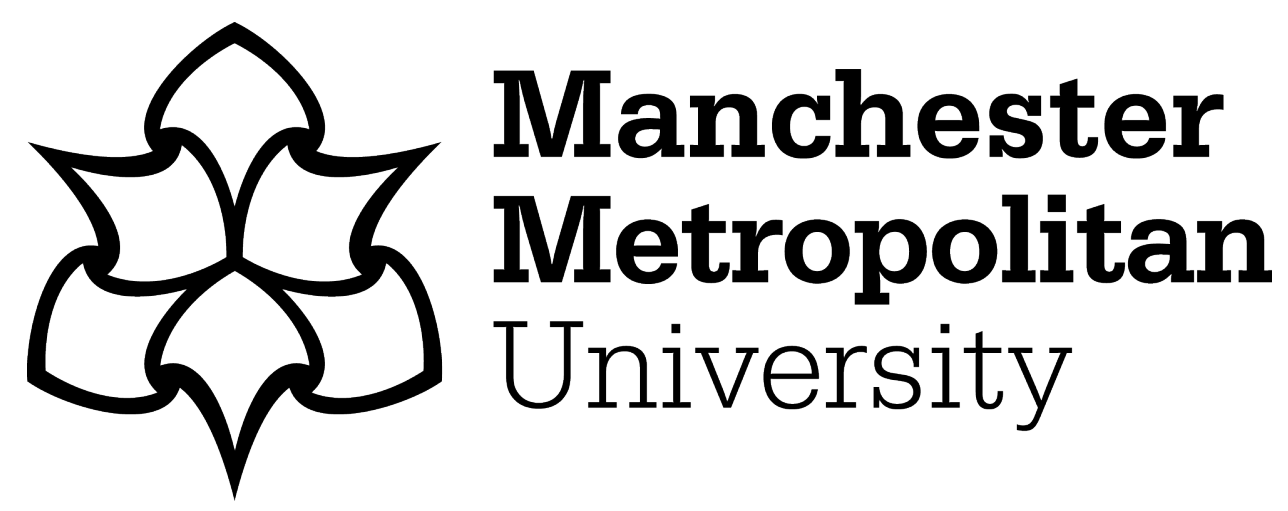

Lee, David M and Tetley, Josie (2019) Sleep quality, sleep duration and sexual health among older people: findings from the English Longitudinal Study of Ageing. Archives of Gerontology and Geriatrics, 82. pp. 147-154. ISSN 0167-4943

Downloaded from: https://e-space.mmu.ac.uk/622477/

Version: Accepted Version

Publisher: Elsevier BV

DOI: https://doi.org/10.1016/j.archger.2019.02.010

Usage rights: Creative Commons: Attribution-Noncommercial-No Derivative Works 4.0

Please cite the published version 


\section{Sleep quality, sleep duration and sexual health among older people: findings from the English Longitudinal Study of Ageing}

David M. Lee and Josie Tetley

Faculty of Health, Psychology and Social Care, Manchester Metropolitan

University, Manchester, United Kingdom.

Correspondence should be addressed to David M. Lee, PhD, Faculty of Health, Psychology and Social Care, Manchester Metropolitan University, Brooks Building, Manchester, M15 6GX, United Kingdom.

E-mail: david.m.lee@mmu.ac.uk

Tel: $+44(0) 1612472412$

Highlights

- Subjective sleep quality was associated with self-reported poorer sexual health and sexual satisfaction.

- Self-reported sleep duration was largely unrelated to sexual activities, functioning and satisfaction.

- Robust associations between poorer sleep quality and vaginal pain and vaginal dryness were observed in women. 


\begin{abstract}
Context: How sleep quality and sexual health are associated among community-dwelling individuals remains largely unknown.
\end{abstract}

Objective: We examined the association of sleep disturbance and sleep duration with a range of measures assessing sexual activities, functioning and concerns in a representative sample of older people.

Methods: Participants were community-dwelling adults aged 50-90+ years from wave 6 (2012/2013) of the English Longitudinal Study of Ageing (ELSA) who reported any sexual activity in the last year. Sleep disturbance, sleep duration and sexual health were measured by self-report at wave 6. Retrospective reports of restless sleep (waves 1-6 [2002-2013]) were also examined. The association between sleep measures and sexual health was assessed using logistic regressions stratified by gender and adjusted for demographic, health and lifestyle factors with results expressed as odds ratios (OR) and 95\% confidence intervals (CI).

Results: Among both men and women disturbed sleep was associated with reported declines in sexual activity and function over the last year, and increased concern about their sexual desire, frequency of sexual activity and sexual functioning. Robust associations between high sleep disturbance and vaginal pain $(\mathrm{OR}=1.67,95 \% \mathrm{CI}=1.21,2.31)$ and vaginal dryness $(\mathrm{OR}=1.69,95 \% \mathrm{CI}=1.24,2.30)$ were also observed among women. Retrospective reports of restless sleep showed a dose-response relationship with reported declines in sexual health over the last year, and increased concerns about sexual expression and functioning.

Conclusions: Self-reported sleep disturbance and retrospective restless sleep were mainly associated with subjective assessments of recent declines in sexual activity and functioning, and higher levels of sexual concerns. 


\section{Introduction}

Sleep quality and duration are recognised as important for health, but many adults experience disturbed sleep and do not obtain the recommended 7 to 9 hours of sleep per night (Hirshkowitz et al., 2015a; Hirshkowitz et al., 2015b). Although estimates are variable numerous studies in Europe have indicated that over a third of adults aged 60 and over experience some degree of insomnia (Léger et al., 2008). Factors compromising sleep quality are diverse and include sedentary lifestyles, shift work, social jetlag and psychological stress (Berkman et al., 2015; Islam et al., 2018; Pallesen et al., 2001; Yang et al., 2017). Previous studies have consistently associated poor sleep quality among older adults with a variety of unfavourable health outcomes such as cardiovascular disease, depression, frailty, type 2 diabetes, cognitive impairment and an increased risk of mortality (Beydoun et al., 2017; Jackowska and Steptoe, 2015; Kanagasabai and Chaput, 2017; Mallon et al., 2005; Miller et al., 2014; Nakakubo et al., 2018). However, the causal relationships connecting sleep quality and duration with health and wellbeing outcomes remain poorly understood.

Positive aspects of close personal relationships have been associated with improved sleep quality and health outcomes (Chen et al., 2015; Umberson et al., 2006). Sexual activities and intimacy form an integral part of many older people's coupled relationship and good sexual health and positive sexual expression have been shown to be associated with positive indicators of emotional wellbeing and quality of life in both men and women (Lee et al., 2016b). While there is a significant research literature describing comorbidities associated with sleep disorders and poor quality sleep, potential links to sexual health and expression remain under researched. An improved understanding of the relationship between older adults' sleep quality and their intimate sexual lives may have practical application in better promoting broader health and wellbeing in later life. 
Where previous research has examined the associations between sleep and sexual health it has tended to focus on identifiable sleep disorders and/or specific problems with sexual functioning. For example, Martin and colleagues found a strong, independent relationship between objective measures of sleep, such as obstructive sleep apnoea (OSA), and erectile dysfunction (ED) in men 65 years and older (Martin et al., 2017). Similarly, Andersen and colleagues showed that men (aged 20-80 years) enrolled in the Epidemiologic Sleep Study, who had measurably reduced time spent in REM sleep or fragmented sleep, were at a significantly higher risk of reporting ED complaints (Andersen et al., 2010). Among women, Onem and colleagues observed a significant decrease in female sexual function, assessed using the Female Sexual Function Index (FSFI) questionnaire, among those with obstructive sleep apnoea-hypopnea syndrome (OSA-HS) (Onem et al., 2008).

Clearly, the majority of extant research has focussed either on clinical samples or on relatively small, non-representative samples, with inherent limitations also reflected in the restrictive range of sexual health measures typically included. The extent to which sleep quality and sexual health are associated among generally healthy, community-dwelling individuals remains largely unknown.

In this study we used data from the $6^{\text {th }}$ wave of the English Longitudinal Study of Ageing (ELSA), a panel survey of ageing, retirement and health in middle-aged and older men and women, to examine the association between sleep quality (self-reported sleep disturbance and sleep duration) and a range of measures assessing sexual activities, functioning and concerns. We also investigated the association between retrospective reports of sleep quality (ELSA waves 1 to 6) and sexual health. We hypothesised that individuals reporting poor sleep quality would have worse sexual health in terms of a lower frequency of sexual activities and a higher prevalence of sexual difficulties and concerns, compared to those reporting better sleep quality. We also anticipated that there would be evidence of a dose response 
relationship, i.e., poorer self-reported sleep quality would be associated with increasingly poorer sexual health outcomes.

\section{Methods}

\subsection{Participants and Study Design}

The main analysis data were from wave 6 (2012/2013) of ELSA, a nationally representative longitudinal panel survey of community-dwelling men and women aged 50 years and older in England (Steptoe et al., 2013). Data collection consisted of a computer-assisted personal interview (CAPI) and self-completion questionnaires. The general methods of data collection are detailed at http://www.elsa-project.ac.uk. A total 7,079 (67\%) participants completed and returned the paper based Sexual Relationships and Activities Questionnaire (SRA-Q). We restricted this analysis to ELSA members who reported any sexual activity in the last 12 months, had complete sleep data at wave 6 , and for whom sampling probability weights were available (see below), leaving 3,803 individuals in the main analysis sample. Item nonresponse was less than $1 \%$ for the sexual health variables included here. ELSA wave 6 received ethical approval from the National Research Ethics Service Committee South Central - Berkshire, United Kingdom, and all participants provided written informed consent.

\subsection{Sleep measures}

Questions on sleep problems and sleep duration were asked during the CAPI. Participants were asked about sleep problems using four questions assessing common symptoms of insomnia. Specifically, these were 'how often the respondent has difficulty falling asleep', 'frequency of waking up at night', 'difficulty staying asleep' and 'frequency of waking up feeling tired and worn out'. Each of these items was scored on a four-point scale ranging from 1 (not during the last month) to 4 (three or more times a week). The four scores were 
averaged to yield a composite sleep disturbance score with higher values denoting greater sleep disturbance. Cronbach's alpha was 0.72 in this sample and the sleep disturbance score was divided into gender-specific tertiles prior to analysis $\left(1^{\text {st }}\right.$ tertile $=$ minimal sleep disturbance, $2^{\text {nd }}$ tertile $=$ moderate sleep disturbance, $3^{\text {rd }}$ tertile $=$ high sleep disturbance) . Sleep duration was assessed using an open-ended question asking participants how many hours sleep they typically had on an average week night. Sleep duration was categorised into $\leq 6$ hours (short duration), $>6$ to 8 hours (average duration) and $>8$ hours (long duration). Participants also provided information on self-rated sleep quality over previous biennial waves of data collection (waves 1-6), using the question 'whether respondents felt their sleep was restless during the past week' $(0=$ no, $1=$ yes $)$. From this binary outcome we generated an additional retrospective variable categorising those with 'no reported restless sleep', 'restless sleep reported at 1 or 2 waves' or 'restless sleep reported at 3 waves or more'.

\subsection{Sexual Activities, Problems and Concerns}

The ELSA SRA-Q included in-depth questions on frequency of sexual activities, sexual functioning and difficulties, concerns about sexual health and changes in sexual health over the last 12 months. Table 1 summarises the items from the SRA-Q used in this analysis. Participants completed the SRA-Q in confidence and returned it in a sealed envelope. The full range of sexuality measures assessed in the SRA-Q and cross-sectional associations with demographic, lifestyle, and health factors have been described previously (Lee et al., 2016a). The SRA-Q instrument is freely available at http://www.elsa-project.ac.uk/documentation.

\subsection{Other Assessments}

During the face-to-face interview participants were asked about their current living arrangements, the age at which they left education, frequency of vigorous/moderate physical 
activity, frequency of being troubled with pain, self-rated general health and whether they had a doctor diagnosis of high blood pressure, heart conditions, arthritis, diabetes, asthma, chronic lung conditions, or if they had ever suffered a stroke or been diagnosed with cancer. A morbidity count variable was also created categorised as none, one, two, three or more chronic conditions. Smoking status was recorded as current or non-smoker, and typical frequency of alcohol consumption over the past year as never or rarely (never-once or twice), regularly (once every 2 months-twice a week) or frequently (3 days a week-almost every day). Depressive symptoms were assessed using the eight-item version of the Center for Epidemiologic Studies Depression scale (CES-D), with a score of four or more indicative of likely depression (Radloff, 1977).

\subsection{Statistical Analysis}

Analyses were conducted using STATA SE v15.1 (StataCorp, College Station, TX). Sampling weights were used to correct for sampling probabilities and differential nonresponse, including to the SRA-Q, and to calibrate back to the 2011 Census population distributions for gender and age. Specifically, these weights accounted for (i) the differential probability of being included in the wave 6 sample and (ii) for non-response to the SRA-Q instrument (full details available from http://www.elsa-project.ac.uk). Logistic regressions adjusted for age, partner status, age left education, self-rated health, depression, physical activity level, pain, smoking status and frequency of alcohol consumption were used to determine the association of both sleep measures at wave 6 (sleep disturbance and sleep duration) and retrospective sleep quality (no reported restless sleep, restless sleep reported at 1 or 2 waves, restless sleep reported at 3 waves or more) with sexual activities, difficulties and concerns, separately by gender. For the sexual health variables with four or five response categories (see Table 1) ordinal logistic regressions (proportional odds models) were used, 
while the two category outcomes were modelled using binary logistic regressions. Ordinal logistic regression is an extension of logistic regression, and the resulting coefficient for a given predictor represents the odds of being in a higher outcome category associated with a unit increase in the value of that variable (Hosmer and Lemeshow, 1989). Non-violation of the parallel slope assumption of the ordinal logistic models was assessed using the Brant test in Stata. A complete confounder analysis is presented in Appendices 1 to 4, supporting the rationale for the inclusion of the adjustment variables in the final logistic regression models. All results were expressed as odds ratios (OR) and 95\% confidence intervals (CI).

\section{Results}

\subsection{Demographics}

Table 2 summarises the demographic, health and lifestyle characteristics of the wave 6 analysis sample who reported any sexual activity in the last 12 months. Men were more likely to have left education beyond 18 years of age and consumed alcohol more frequently, as compared to women (all $p<0.05$ ). Women were more likely than men to report often being troubled with pain $(p<0.05)$.

\subsection{Sleep measures}

Sleep measures collected at both wave 6 and retrospectively (waves 1-6) are summarised in Table 3. Overall, women had a scored higher on the sleep disturbance scale (Wilcoxon ranksum test; $p<0.001$ ), but there was no significant differences by gender for typical hours of sleep on an average week night. A total of 3,267 participants had complete retrospective sleep data from wave 1 to wave 6 and women with proportionally more women reporting restless sleep at three waves or more $(36.5 \%)$ as compared to men $(23.4 \% ; p<0.05)$. 


\subsection{Sleep quality, sleep duration and any sexual activity}

As reported previously, of the 6,201 core ELSA members (excluding partners who were aged less than 50 and those aged 50 or over without sampling weights) with SRA-Q data, $54 \%$ of women and $78 \%$ of men reported any sexual activity in the last year (ref). Although the main analysis here was restricted to those participants who reported 'any' sexual activity in the last 12 months and with complete sleep data at wave 6, we also examined whether there were any associations between the sleep measures used here and the likelihood of reporting 'any' sexual active over the last year. Using binary logistic regressions (adjusted for the same demographic, health and lifestyle covariates as outlined in the methods above) we found that among men there was no significant association between either moderate sleep disturbance $(\mathrm{OR}=1.14 ; 95 \% \mathrm{CI} 0.86,1.50)$ or high sleep disturbance $(\mathrm{OR}=1.01 ; 95 \% \mathrm{CI} 0.71,1.67)$ and the likelihood of reporting any sexual activity in the last 12 months. This lack of association was also seen in women for both moderate sleep disturbance $(\mathrm{OR}=1.23 ; 95 \% \mathrm{CI} 0.98,1.55)$ and high sleep disturbance $(\mathrm{OR}=1.11 ; 95 \% \mathrm{CI} 0.86,1.43)$. Similarly, there were no significant associations observed between the likelihood of reporting any sexual activity in the last 12 months, and either short or long sleep duration in both men and women (data not shown; all $p>0.05$ ). Appendix 5 summarises the frequency of key sexual health outcomes by sleep disturbance category in men and women reporting any sexual activity in the last 12 months (sample sizes as in Table 2).

\subsection{Sleep quality, sleep duration and sexual health (ELSA wave 6)}

Associations between sleep measures and sexual activities, difficulties and concerns differed by both gender, and whether sleep disturbance was categorised as moderate or high (Table 4). After adjustment for demographic, health and lifestyle factors, compared to men 
with minimal sleep disturbance, men with moderate or high sleep disturbance were more likely to report declines in their ability to attain an erection over the last year and had increased concerns about their levels of sexual desire, frequency of sexual activities, ability to have an erection and their overall sex lives. Men in the moderate sleep disturbance group were also significantly more likely to report increased difficulty achieving an erection (OR = $1.40, p=0.006)$ and declines in the frequency of sexual activities over the last year $(\mathrm{OR}=$ $1.44, p=0.010)$. In contrast, men in the high sleep disturbance group were more likely to report an increased frequency of thinking about sex $(\mathrm{OR}=1.5, p=0.012)$ and declines in their sexual drive over the last year $(\mathrm{OR}=1.51, p=0.011)$. When considering measures of sleep duration, significant associations were only observed among men reporting long sleep duration and a reduced frequency of sexual intercourse $(\mathrm{OR}=0.63, p=0.033)$, and long sleep duration and an increased decline in sexual drive over the last year $(\mathrm{OR}=1.77, p=0.014)$. Compared to women reporting minimal sleep disturbance, women with moderate or high sleep disturbance were more likely to report an increased difficulty becoming sexually aroused, increased experience of pain during sexual activity, more likely to report declines in their ability to become sexually aroused over the last year, and reported increased concern about their overall sex lives (see Table 4). Women in the high sleep disturbance group were also more likely to report a decreased frequency of sexual intercourse $(\mathrm{OR}=0.76, p=0.018)$, increased experience of vaginal dryness during sexual activity $(\mathrm{OR}=1.69, p=0.001)$ and declines in their sexual drive $(\mathrm{OR}=1.63, p=0.003)$ and frequency of sexual activities $(\mathrm{OR}=$ $1.46, p=0.016$ ) over the last year. Women in the high sleep disturbance group additionally reported increased concern about their levels of sexual desire $(\mathrm{OR}=1.57, p=0.007)$ and ability to have an orgasm $(\mathrm{OR}=1.65, p=0.020)$. In contrast to men, when considering measures of sleep duration among women no significant associations were observed with any sexual health outcomes. 


\subsection{Retrospective sleep quality and sexual health (ELSA waves 1-6)}

Associations between retrospective measures of sleep quality and sexual activities, difficulties and concerns are summarised in Table 5. For both men and women the majority of significant associations with sexual health outcomes were restricted to those participants reporting restless sleep at three waves of data collection or more, as compared to participants reporting no restless sleep at any wave. For both sexes, consistent associations between restless sleep at three waves or more were observed with declines in sexual drive, activities and function over the last year, and with increased levels of concern about sexual drive, activities and function. In addition, robust associations were observed among women reporting restless sleep at one or two waves or restless sleep at three waves or more, and both increased experience of pain during sexual activity and increased experience of vaginal dryness during sexual activity. Compared to those reporting no restless sleep at any wave, women reporting restless sleep at three waves or more were more likely to have difficulty becoming sexually aroused $(\mathrm{OR}=1.40, p=0.031)$; men reporting restless sleep at one or two waves were more likely to report thinking about $\operatorname{sex}(\mathrm{OR}=1.34, p=0.030)$, and men reporting restless sleep at three waves or more were more likely to masturbate $(\mathrm{OR}=1.37, p$ $=0.018)$.

\section{Discussion}

These nationally representative data from ELSA reveal robust, independent associations between self-reported sleep disturbance and a variety of poorer sexual health outcomes among older men and women in England. After adjusting for demographic, health and lifestyle factors men and women reporting moderate or high sleep disturbance cross-sectionally, or 
more restless sleep retrospectively, were significantly more likely to report declines in their sexual health over the last year and also increased levels of concern about aspects of their sexual lives. Associations between sleep disturbance and/or restless sleep and sexual activities and function were less apparent in both sexes, although significant functional difficulties in women (pain and vaginal dryness) were consistently observed.

Our findings extend significantly on previous work showing that measures of sleep quality and specific sleep disorders can have a marked negative effect on aspects of sexual health. We clearly found the most consistent associations to be between subjective indices of sleep quality (sleep disturbance at wave 6, restless sleep at waves 1-6) and sexual health outcomes reflecting perceived temporal declines in, and current concerns with, sexual expression and function. This suggests that the observed relationships between sleep and sexual health may in part be mediated by adverse psychological factors. Indeed, previous research has highlighted predictable patterns of association between both stress and anxiety disorders and insomnia (Seehuus and Pigeon, 2018), and stress is also known to adversely contribute to sexual function (Laumann et al., 2006; Laumann et al., 1999). While ELSA did not include instruments assessing stress and/or anxiety, depressive symptoms were assessed using the eight-item CES-D scale, and we found that depression was significantly associated with both higher sleep disturbance and poorer sexual health ( $p<0.05$, data not shown). However, many associations between sleep and sexual health remained statistically significant in our multivariate analyses after accounting for the shared influence of this measure of mental health. Further research is warranted to ascertain whether this is due to residual confounding or omission of key explanatory covariates.

With respect to measures of sexual expression and functioning we observed few significant associations with either sleep quality or duration. Using data from the population-based Epidemiologic Sleep Study (EPISONO), Andersen and colleagues (Andersen et al., 2010) 
found that reduced time spent in REM sleep, fragmented sleep and OSA were significantly associated with a higher risk of ED. A number of other studies have similarly found that ED is often associated with sleep disorders and sleep apnoea, particularly among middle-aged and older men (Heruti et al., 2005; Martin et al., 2017; Seehuus and Pigeon, 2018). In contrast, we only observed a significant association between sleep quality and ED among men reporting moderate sleep disturbance. This may reflect the variety of sleep problems likely captured by the subjective question on sleep disturbance used here, as compared to objective measures of OSA and related conditions, with the non-specificity of the underlying sleep aetiologies in ELSA tending to reduce the reported associations between sleep and ED toward the null rather than produce spurious associations. We did observe robust associations between subjective sleep quality and vaginal pain and dryness among women. The literature describing the relationship between the menopause and both sleep problems (Eichling and Sahni, 2005) and changes in sexual health (Dennerstein et al., 2003) is extensive and beyond the scope of detailed discussion here. Endocrine changes, particularly modulation of oestradiols and androgens levels post-menopause, have been shown to be associated with declines in libido and subjective arousal, via direct and indirect mechanisms (Andersen et al., 2011; Dennerstein et al., 2002; Schwenkhagen, 2007). Using data from the Women's Health Initiative (WHI) Observational Study, Kling and colleagues observed robust cross-sectional associations between shorter sleep durations and higher insomnia scores and decreased partnered sexual activity and sexual satisfaction (Kling et al., 2017). Sleep problems have been reported to be most problematic among women during the menopausal transition and early post-menopause (Dennerstein et al., 2000; Kravitz et al., 2003; Kravitz et al., 2008; Woods and Mitchell, 2010). The female participants in the ELSA analysis sample were overwhelmingly (94.3\%) post-menopausal (as assessed by the question: whether menstruated in the last 12 months). Restricting the logistic regression models to those women aged 60 and 
over at wave $6(99.6 \%$ post-menopausal in our sample) did not substantively change the pattern of associations observed in Table 4 (results not shown). This suggests, at least partly, that those women most likely to be undergoing the menopausal transition weren't disproportionately explaining the significant associations observed. In relation to possible endocrinological confounding, a total of $113(6.3 \%)$ reported ever having used hormone replacement therapy. Additionally adjusting the logistic regression models for HRT usage (or excluding those cases) did not substantively change the pattern of associations observed in Table 4 or Table 5 (results not shown).

Although we observed more significant associations between high sleep disturbance and sexual health outcomes, as compared to moderate sleep disturbance, our cross-sectional (wave 6) findings did not reveal robust evidence of a dose response relationship between poorer selfreported sleep quality and poorer sexual health. However, the retrospective sleep quality data (waves 1-6) did show a clearer dose response, with consistent associations observed for declines in sexual activities and function over the last year and concerns about sexual activities and function among those participants having restless sleep at three waves or more, versus those reporting restless sleep at one or two waves. Although the four cross-sectional questions used to assess sleep disturbance at wave 6 are likely capturing different information than the retrospective single question assessing restless sleep, the data nonetheless point to prolonged periods of poor quality sleep being particularly detrimental with respect to the sexual health outcomes measured here. However, as we don't have longitudinal data on sexual health it is unknown whether those reporting poor sleep quality at wave 6 were more or less sexually active in the past than those reporting better sleep quality. Nonetheless, individuals with higher sleep disturbance/poorer sleep quality (cross-sectionally and retrospectively) were more likely to report greater sexual concerns and retrospective reports 
of declines in sexual expression and functioning, if not so marked impacts on current sexual activities.

Interestingly we found little evidence of associations between sleep duration and sexual health. Although the measures of sleep disturbance and sleep duration overlap to some extent (the correlation between sleep disturbance and sleep duration [continuous variables] was moderate; Spearman's rho $=0.38, p<0.05)$, there is a qualitative difference between them. Previous research has shown that sleep quality may be better related to measures of health and wellbeing, than sleep quantity in a non-clinical, albeit younger, population reporting an average of 7-8 hours of sleep per night (Pilcher et al., 1997). Van den Berg and colleagues (Van Den Berg et al., 2008) also found that in a population-based study of communitydwelling elderly adults, just over a third of participants did not estimate their sleep duration in a diary within a range of one hour from their actigraphically measured total sleep time. If such misclassification has occurred in the ELSA sample it may have sufficiently biased the observed results towards the null. When the sleep duration variable was included in the logistic regression models as a continuous variable (range $=2-12$ hours) no substantive changes in statistical significance were observed (results not shown). An alternative explanation may be that while sleep duration does not differ markedly between younger and older adults, sleep continuity and efficiency have been shown to deteriorate with increasing age (Ancoli-Israel, 2009), therefore explaining why our significant associations were restricted to subjective measures of sleep quality.

The complex physiological, psychological and/or social mechanisms linking sleep quality and sexual health remain poorly defined and we were unable to directly investigate them here. As discussed above, it is plausible that coexistent health factors are, at least in part, mediating the observed associations between sleep quality and sexual health (for example depression), and it is possible that this in turn may be partly driven by detrimental effects of sleep 
problems on quality of life and subjective wellbeing (Steptoe et al., 2008). ELSA has gathered self-report information on various gynaecological and urological factors (hysterectomy, oophorectomy, diagnosed prostate cancer, and urinary incontinence) which have been shown to impact sexual health and could also possibly effect sleep quality/disturbance. However, additionally adjusting the logistic regression models for these potentially confounding gynaecological/urological factors (or dropping affected cases) did not substantively change the reported results (results not shown).

The ELSA study has a number of methodological strengths; the data were gathered from a large and representative community-dwelling sample covering midlife to the oldest old, who were not recruited explicitly to answer questions on their sexual health. Our data extend the upper age limits around one to two decades above that typically included in other populationbased studies, whilst also capturing detailed information regarding sexual activities, problems and satisfaction. Although limitations of the study have been described (Steptoe et al., 2013), certain factors need to be highlighted here. The self-report sleep questions did not provide objective measures of sleep disturbance and did not attempt to differentiate between sleep disturbance subtypes (OSA, OSA-HS, sleep fragmentation, hypoxaemia etc.). Further exploration of potential differential relationships across different aspects of sleep quality/disturbance would require more exhaustive questionnaire items than the ELSA schedule allowed. ELSA did not oversample ethnic or sexual minority groups and the results presented here may not be generalisable to ethnic minority, and lesbian, gay and other groups who do not identify themselves as heterosexual. Those ELSA participants who chose not to complete the SRA-Q may not have done so due to pre-existing sexual problems and/or feeling that they were 'retired' from sex. The non-response weights will have partly dealt with this, with weighting for non-response to the SRA-Q directly accounting for the variation in response according to demographic and health characteristics. These weights, however, 
would not have dealt with sleep and/or sexual health characteristics that were unrelated to the factors used for weighting. Finally, the ELSA wave 6 SRA-Q data preclude any examination of the temporal nature of the observed associations between sleep and sexual health. While it seems likely that the relationships between sleep and sexual health are bidirectional, i.e., sleep quality impacts on sexual health and sexual health impacts on sleep quality, any determination of the temporal nature of the associations cannot be answered in the context of these crosssectional data. In addition, the lack of longitudinal data on sexual health prevents us examining whether those reporting poorer sleep quality at wave 6 were more or less sexually active in the past than those reporting no sleep disturbance. Longer-term, prospective data will allow for an examination of the temporal relationships between sleep quality/disturbance and sexual health/wellbeing, using cross-lagged panel approaches to simultaneously model reciprocal and longitudinal associations among a range of interrelated variables.

In conclusion, poor sleep quality was negatively associated with diverse aspects of sexual health in both men and women, mainly relating to self-reported declines in sexual activity and functioning over the last year, and higher levels of sexual concerns. Robust associations between sleep quality and sexual difficulties were also observed in women. Given the high population prevalence of sleep problems and disturbance, particularly among postmenopausal women, health care professionals should consider the potential combinatorial effects of sexual wellbeing and satisfaction. A more inclusive clinical recognition of the links between sleep quality and sexual health could result in more comprehensive and effective treatment for both outcomes.

\section{Acknowledgements}

DML was an Age UK Research into Ageing Fellow [Research Fellowship 365] for part of this work. ELSA was funded by the National Institute on Aging [grants 2RO1AG7644-01A1 
and 2RO1AG017644] and a consortium of UK Government departments coordinated by the

Office for National Statistics.

\section{Conflict of Interest}

None declared.

Data sharing: The ELSA datasets are publicly available from the UK Data Service at www.ukdataservice.ac.uk. ELSA documentation (including questionnaires) are available from the Institute for Fiscal Studies at http://www.ifs.org.uk/ELSA. Stata ${ }^{\circledR}$ do.files are available from DML at david.m.lee@mmu.ac.uk

\section{References}

Ancoli-Israel, S., 2009, Sleep and its disorders in aging populations: Sleep Med, v. 10 Suppl 1, p. S711.

Andersen, M. L., T. F. Alvarenga, R. Mazaro-Costa, H. C. Hachul, and S. Tufik, 2011, The association of testosterone, sleep, and sexual function in men and women: Brain Res, v. 1416, p. 80-104.

Andersen, M. L., R. Santos-Silva, L. R. Bittencourt, and S. Tufik, 2010, Prevalence of erectile dysfunction complaints associated with sleep disturbances in Sao Paulo, Brazil: a populationbased survey: Sleep Med, v. 11, p. 1019-24.

Berkman, L. F., S. Y. Liu, L. Hammer, P. Moen, L. C. Klein, E. Kelly, M. Fay, K. Davis, M. Durham, G. Karuntzos, and O. M. Buxton, 2015, Work-family conflict, cardiometabolic risk, and sleep duration in nursing employees: J Occup Health Psychol, v. 20, p. 420-33.

Beydoun, H. A., M. A. Beydoun, X. Chen, J. J. Chang, A. A. Gamaldo, S. M. Eid, and A. B. Zonderman, 2017, Sex and age differences in the associations between sleep behaviors and all-cause mortality in older adults: results from the National Health and Nutrition Examination Surveys: Sleep Med, v. 36, p. 141-151.

Chen, J. H., L. J. Waite, and D. S. Lauderdale, 2015, Marriage, Relationship Quality, and Sleep among U.S. Older Adults: J Health Soc Behav, v. 56, p. 356-77.

Dennerstein, L., J. L. Alexander, and K. Kotz, 2003, The menopause and sexual functioning: a review of the population-based studies: Annu Rev Sex Res, v. 14, p. 64-82.

Dennerstein, L., E. C. Dudley, J. L. Hopper, J. R. Guthrie, and H. G. Burger, 2000, A prospective population-based study of menopausal symptoms: Obstet Gynecol, v. 96, p. 351-8.

Dennerstein, L., J. Randolph, J. Taffe, E. Dudley, and H. Burger, 2002, Hormones, mood, sexuality, and the menopausal transition: Fertil Steril, v. 77 Suppl 4, p. S42-8.

Hosmer, D. W., and Lemeshow, S., 1989, Applied logistic regression: New York, John Wiley, Sons.

Eichling, P. S., and J. Sahni, 2005, Menopause related sleep disorders: J Clin Sleep Med, v. 1, p. 291300.

Heruti, R., T. Shochat, D. Tekes-Manova, I. Ashkenazi, and D. Justo, 2005, Association between erectile dysfunction and sleep disorders measured by self-assessment questionnaires in adult men: J Sex Med, v. 2, p. 543-50. 
Hirshkowitz, M., K. Whiton, S. M. Albert, C. Alessi, O. Bruni, L. DonCarlos, N. Hazen, J. Herman, P. J. Adams Hillard, E. S. Katz, L. Kheirandish-Gozal, D. N. Neubauer, A. E. O'Donnell, M. Ohayon, J. Peever, R. Rawding, R. C. Sachdeva, B. Setters, M. V. Vitiello, and J. C. Ware, 2015a, National Sleep Foundation's updated sleep duration recommendations: final report: Sleep Health, v. 1, p. 233-243.

Hirshkowitz, M., K. Whiton, S. M. Albert, C. Alessi, O. Bruni, L. DonCarlos, N. Hazen, J. Herman, E. S. Katz, L. Kheirandish-Gozal, D. N. Neubauer, A. E. O'Donnell, M. Ohayon, J. Peever, R. Rawding, R. C. Sachdeva, B. Setters, M. V. Vitiello, J. C. Ware, and P. J. Adams Hillard, 2015b, National Sleep Foundation's sleep time duration recommendations: methodology and results summary: Sleep Health, v. 1, p. 40-43.

Islam, Z., S. Akter, T. Kochi, H. Hu, M. Eguchi, M. Yamaguchi, K. Kuwahara, I. Kabe, and T. Mizoue, 2018, Association of social jetlag with metabolic syndrome among Japanese working population: the Furukawa Nutrition and Health Study: Sleep Med, v. 51, p. 53-58.

Jackowska, M., and A. Steptoe, 2015, Sleep and future cardiovascular risk: prospective analysis from the English Longitudinal Study of Ageing: Sleep Med, v. 16, p. 768-74.

Kanagasabai, T., and J. P. Chaput, 2017, Sleep duration and the associated cardiometabolic risk scores in adults: Sleep Health, v. 3, p. 195-203.

Kling, J. M., J. E. Manson, M. J. Naughton, M. Temkit, S. D. Sullivan, E. W. Gower, L. Hale, J. C. Weitlauf, S. Nowakowski, and C. J. Crandall, 2017, Association of sleep disturbance and sexual function in postmenopausal women: Menopause, v. 24, p. 604-612.

Kravitz, H. M., P. A. Ganz, J. Bromberger, L. H. Powell, K. Sutton-Tyrrell, and P. M. Meyer, 2003, Sleep difficulty in women at midlife: a community survey of sleep and the menopausal transition: Menopause, v. 10, p. 19-28.

Kravitz, H. M., X. Zhao, J. T. Bromberger, E. B. Gold, M. H. Hall, K. A. Matthews, and M. R. Sowers, 2008, Sleep disturbance during the menopausal transition in a multi-ethnic community sample of women: Sleep, v. 31, p. 979-90.

Radloff, L. S., 1977, The CES-D scale: a self report depression scale for research in the general population: Appl. Psychol. Meas, v. 1, p. 385-401.

Laumann, E. O., A. Paik, D. B. Glasser, J. H. Kang, T. Wang, B. Levinson, E. D. Moreira, A. Nicolosi, and C. Gingell, 2006, A cross-national study of subjective sexual well-being among older women and men: findings from the Global Study of Sexual Attitudes and Behaviors: Arch Sex Behav, v. 35 , p. $145-61$.

Laumann, E. O., A. Paik, and R. C. Rosen, 1999, Sexual dysfunction in the United States: prevalence and predictors: JAMA, v. 281, p. 537-44.

Lee, D. M., J. Nazroo, D. B. O'Connor, M. Blake, and N. Pendleton, 2016a, Sexual Health and Wellbeing Among Older Men and Women in England: Findings from the English Longitudinal Study of Ageing: Arch Sex Behav, v. 45, p. 133-44.

Lee, D. M., B. Vanhoutte, J. Nazroo, and N. Pendleton, 2016b, Sexual Health and Positive Subjective Well-Being in Partnered Older Men and Women: J Gerontol B Psychol Sci Soc Sci, v. 71, p. 698-710.

Léger, D., B. Poursain, D. Neubauer, and M. Uchiyama, 2008, An international survey of sleeping problems in the general population: Curr Med Res Opin, v. 24, p. 307-17.

Mallon, L., J. E. Broman, and J. Hetta, 2005, High incidence of diabetes in men with sleep complaints or short sleep duration: a 12-year follow-up study of a middle-aged population: Diabetes Care, v. 28, p. 2762-7.

Martin, S. A., S. L. Appleton, R. J. Adams, A. W. Taylor, A. Vincent, N. R. Brook, P. G. Catcheside, A. Vakulin, R. D. McEvoy, N. A. Antic, and G. A. Wittert, 2017, Erectile dysfunction is independently associated with apnea-hypopnea index and oxygen desaturation index in elderly, but not younger, community-dwelling men: Sleep Health, v. 3, p. 250-256.

Miller, M. A., H. Wright, C. Ji, and F. P. Cappuccio, 2014, Cross-sectional study of sleep quantity and quality and amnestic and non-amnestic cognitive function in an ageing population: the English Longitudinal Study of Ageing (ELSA): PLoS One, v. 9, p. e100991. 
Nakakubo, S., H. Makizako, T. Doi, K. Tsutsumimoto, R. Hotta, S. Lee, S. Bae, K. Makino, T. Suzuki, and H. Shimada, 2018, Long and Short Sleep Duration and Physical Frailty in Community-Dwelling Older Adults: J Nutr Health Aging, v. 22, p. 1066-1071.

Onem, K., B. Erol, O. Sanli, P. Kadioglu, A. S. Yalin, U. Canik, C. Cuhadaroglu, and A. Kadioglu, 2008, Is sexual dysfunction in women with obstructive sleep apnea-hypopnea syndrome associated with the severity of the disease? A pilot study: I Sex Med, v. 5, p. 2600-9.

Pallesen, S., I. H. Nordhus, G. H. Nielsen, O. E. Havik, G. Kvale, B. H. Johnsen, and S. Skjøtskift, 2001, Prevalence of insomnia in the adult Norwegian population: Sleep, v. 24, p. 771-9.

Pilcher, J. J., D. R. Ginter, and B. Sadowsky, 1997, Sleep quality versus sleep quantity: relationships between sleep and measures of health, well-being and sleepiness in college students: J Psychosom Res, v. 42, p. 583-96.

Schwenkhagen, A., 2007, Hormonal changes in menopause and implications on sexual health: J Sex Med, v. 4 Suppl 3, p. 220-6.

Seehuus, M., and W. Pigeon, 2018, The sleep and sex survey: Relationships between sexual function and sleep: J Psychosom Res, v. 112, p. 59-65.

Steptoe, A., E. Breeze, J. Banks, and J. Nazroo, 2013, Cohort profile: the English longitudinal study of ageing: Int J Epidemiol, v. 42, p. 1640-8.

Steptoe, A., K. O'Donnell, M. Marmot, and J. Wardle, 2008, Positive affect, psychological well-being, and good sleep: J Psychosom Res, v. 64, p. 409-15.

Umberson, D., K. Williams, D. A. Powers, H. Liu, and B. Needham, 2006, You make me sick: marital quality and health over the life course: J Health Soc Behav, v. 47, p. 1-16.

Van Den Berg, J. F., F. J. Van Rooij, H. Vos, J. H. Tulen, A. Hofman, H. M. Miedema, A. K. Neven, and H. Tiemeier, 2008, Disagreement between subjective and actigraphic measures of sleep duration in a population-based study of elderly persons: J Sleep Res, v. 17, p. 295-302.

Woods, N. F., and E. S. Mitchell, 2010, Sleep symptoms during the menopausal transition and early postmenopause: observations from the Seattle Midlife Women's Health Study: Sleep, v. 33, p. 539-49.

Yang, Y., J. C. Shin, D. Li, and R. An, 2017, Sedentary Behavior and Sleep Problems: a Systematic Review and Meta-Analysis: Int J Behav Med, v. 24, p. 481-492. 
Table $1 \mid$ Principal sexual health variables used in the English Longitudinal Study of Ageing (ELSA)

\section{Topic}

\section{Category coding}

Sexual behaviors/activities (...during the past month)

How often did you think about sex?

How many times have you had or attempted sexual intercourse (vaginal, anal or oral)? How frequently did you engage in other sexual activities (kissing, petting or fondling)?

How often did you masturbate?

\section{Sexual functioning (...during the past month)}

Able to get or keep an erection which would be good enough for sexual activity? (men)

How often did you feel sexually aroused during sexual activity? (women)

5 categories: 'Not at all', 'Once per month, '2-3 times per month', 'Once per week', '2-3 times per week or more'.

4 categories: ‘Always able’, 'Usually able’, 'Sometimes able’, 'Never able’.

5 categories: 'Always', 'Usually', ‘Sometimes', 'Rarely', 'Never'.

5 categories: 'Always', 'Usually', ‘Sometimes', 'Rarely’, ‘Never'.

How often did you experience pain or vaginal dryness during sexual activity? (women)

5 categories: 'Never', 'Rarely’, ‘Sometimes', 'Usually', ‘Always'.

Change in sexual health (...compared with a year ago)

Has your sexual drive changed?

Has the overall frequency of your sexual activities changed?

2 categories: 'Not changed/Increased' vs. 'Decreased'

Has your ability to have an erection changed? (men)

Has your ability to become sexually aroused changed? (women)

\section{Sexual concerns (...during the past month)}

Have you been worried/concerned by your level of sexual desire?

Have you been worried/concerned by the frequency of your sexual activities?

Have you been worried/concerned by your ability to have an erection? (men)

Have you been worried/concerned by your ability to become sexually aroused? (women)

4 categories: 'Not at all worried or concerned', 'Slightly worried or concerned',

Have you been worried/concerned by your ability to have an orgasm?

How worried/concerned have you been about your overall sex life? 


\begin{tabular}{|c|c|c|}
\hline Variable & Men $(n=2004)$ & Women $(n=1799)$ \\
\hline \multirow[t]{2}{*}{ Age, M (SD) yrs. } & $64.6(7.8)$ & $63.5(7.4)$ \\
\hline & \multicolumn{2}{|c|}{ Weighted percentages $(95 \% \mathrm{CI})$} \\
\hline \multicolumn{3}{|l|}{ Current partner } \\
\hline Married/cohabiting & $75.7(73.1,78.0)$ & $76.8(74.4,79.0)$ \\
\hline Divorced/separated & $12.0(10.2,14.0)$ & $13.2(11.4,15.3)$ \\
\hline Never married & $8.7(7.2,10.6)$ & $4.6(3.5,6.0)$ \\
\hline Widowed & $3.6(2.9,4.6)$ & $5.3(4.3,6.5)$ \\
\hline \multicolumn{3}{|l|}{ Educational attainment } \\
\hline Less than 'O'-level or equivalent & $30.5(28.1,33.1)$ & $38.0(35.4,40.8)$ \\
\hline 'O'-level or equivalent & $28.4(25.9,31.0)$ & $33.7(31.1,36.3)$ \\
\hline 'A'-level or higher & $41.1(38.5,43.8)$ & $28.3(25.9,30.8)$ \\
\hline \multicolumn{3}{|l|}{ Self-rated health } \\
\hline Excellent/Very good & $46.4(43.7,49.2)$ & $48.5(45.8,51.3)$ \\
\hline Good & $33.4(30.9,36.0)$ & $32.0(29.5,34.6)$ \\
\hline Fair/Poor & $20.2(18.2,22.3)$ & $19.5(17.4,21.7)$ \\
\hline \multicolumn{3}{|l|}{ Physical activity (PA) } \\
\hline Moderate/vigorous PA at least once per week & $84.7(82.6,86.6)$ & $82.8(80.4,84.9)$ \\
\hline Moderate/vigorous PA less than once per week & $15.3(13.4,17.4)$ & $17.2(15.1,19.5)$ \\
\hline Often troubled with pain & $35.8(33.2,38.4)$ & $44.1(41.4,46.9)$ \\
\hline Diabetes $^{\mathrm{a}}$ & $9.7(8.3,11.2)$ & $6.6(5.3,8.3)$ \\
\hline Cardiovascular disease (heart conditions/stroke) ${ }^{\mathrm{a}}$ & $12.2(10.7,13.9)$ & $8.2(6.9,9.6)$ \\
\hline Depression $^{\mathrm{b}}$ & $9.7(8.1,11.7)$ & $13.5(11.6,15.7)$ \\
\hline Current smoker & $15.0(12.9,17.2)$ & $12.9(11.0,15.0)$ \\
\hline \multicolumn{3}{|l|}{ Frequency of alcohol consumption ${ }^{\mathrm{c}}$} \\
\hline Never/rarely & $17.5(15.4,19.8)$ & $29.8(27.3,32.5)$ \\
\hline Regularly & $58.0(55.3,60.6)$ & $51.6(48.8,54.3)$ \\
\hline Very frequently & $24.6(22.5,26.8)$ & $18.6(16.6,20.7)$ \\
\hline
\end{tabular}

$\mathrm{M}=$ mean: $\mathrm{SD}=$ standard deviation; $\mathrm{CI}=$ confidence interval

${ }^{a}$ Also includes self-reported use of medications to manage these conditions

${ }^{\mathrm{b}}$ CES-D (8-item) score of $\geq 4$

${ }^{\mathrm{c}}$ Frequency of alcohol consumption over the past year (never/rarely $=$ never-once or twice, regularly $=$ once every 2 months-twice a week, very frequently $=3$ days a week-daily) 


\begin{tabular}{lcc}
\hline \multicolumn{3}{l}{ Table 3 $\mid$ Cross-sectional and retrospective sleep variables in ELSA analysis sample } \\
\hline Variable & Men & Women \\
\hline Wave 6 (cross-sectional) & $(\mathrm{n}=2,004)$ & $(\mathrm{n}=1,799)$ \\
Sleep disturbance scale, M (SD) & $2.1(0.8)$ & $2.4(0.9)$ \\
Number of hours sleep week night, M (SD) & $6.9(1.2)$ & $6.9(1.2)$ \\
\cline { 2 - 3 } & \multicolumn{2}{l}{ Weighted percentages $(95 \% \mathrm{CI})$} \\
Sleep hours, categories & $32.1(29.6,34.7)$ & $33.3(30.8,35.9)$ \\
$\quad \leq 6$ h (short duration) & $62.4(59.8,65.0)$ & $59.7(57.0,62.3)$ \\
$\quad>6$ h to 8 h (average duration) & $5.5(4.5,6.7)$ & $7.0(5.7,8.5)$ \\
$\quad>8$ h (long duration) & Weighted percentages $(95 \% \mathrm{CI})$ \\
\hline Waves 1 - 6 (retrospective) & $(\mathrm{n}=1,741)$ & $(\mathrm{n}=1,526)$ \\
Self-reported sleep quality in last 10 years & $41.2(38.7,43.7)$ & $24.5(22.2,26.9)$ \\
$\quad$ No reported restless sleep at any wave & $35.4(33.0,37.9)$ & $39.0(36.3,41.7)$ \\
$\quad$ Restless sleep reported at one or two waves & $23.4(21.3,25.7)$ & $36.5(33.9,39.2)$ \\
$\quad$ Restless sleep reported at three waves or more & &
\end{tabular}

$\mathrm{M}=$ mean: $\mathrm{SD}=$ standard deviation; $\mathrm{CI}=$ confidence interval

Note: The sample size was smaller in the retrospective sleep sample compared to the cross-sectional sample due to case matching ELSA participants between Waves 1 and 6 (see www.elsa-project.ac.uk/timetable for details) 
Table $4 \mid$ Association of sleep disturbance and duration with sexual health variables in men and women reporting 'any' sexual activity in the last 12 months.

Multiple logistic regressions models: weighted odds ratios (95\% confidence intervals). Reference categories = 'Minimal sleep disturbance' or 'Average sleep duration'.

\begin{tabular}{|c|c|c|c|c|c|}
\hline \multirow{2}{*}{ Sexual health variables } & \multicolumn{3}{|c|}{ Sleep Disturbance } & \multicolumn{2}{|c|}{ Sleep Duration } \\
\hline & $\mathrm{n}$ & Moderate & High & Short & Long \\
\hline \multicolumn{6}{|l|}{ Men } \\
\hline Increased frequency of thinking about sex & 1,997 & $1.17(0.90,1.53)$ & $1.50(1.10,2.06)^{*}$ & $1.08(0.82,1.41)$ & $0.94(0.64,1.39)$ \\
\hline Increased frequency of sexual intercourse & 1,985 & $0.96(0.76,1.21)$ & $1.13(0.84,1.51)$ & $0.92(0.72,1.18)$ & $0.63(0.41,0.96)^{*}$ \\
\hline Increased frequency of kissing, fondling and petting & 1,986 & $0.85(0.68,1.07)$ & $0.92(0.70,1.22)$ & $0.97(0.75,1.24)$ & $0.77(0.51,1.17)$ \\
\hline Increased frequency of masturbation & 1,985 & $1.22(0.96,1.54)$ & $1.29(0.96,1.75)$ & $0.88(0.69,1.12)$ & $0.75(0.50,1.13)$ \\
\hline Increased difficulty achieving an erection & 1,997 & $1.40(1.10,1.78)^{* *}$ & $1.12(0.85,1.47)$ & $1.07(0.84,1.37)$ & $1.07(0.66,1.72)$ \\
\hline Increased difficulty achieving orgasm & 1,739 & $1.14(0.87,1.48)$ & $0.98(0.72,1.34)$ & $1.04(0.80,1.36)$ & $0.95(0.58,1.56)$ \\
\hline Decline in sexual drive over last year & 2,001 & $1.28(0.95,1.72)$ & $1.51(1.10,2.08)^{*}$ & $1.12(0.85,1.48)$ & $1.77(1.12,2.80)^{*}$ \\
\hline Decline in frequency of sexual activities over last year & 1,996 & $1.44(1.09,1.89)^{*}$ & $1.21(0.88,1.65)$ & $1.01(0.77,1.32)$ & $1.05(0.68,1.62)$ \\
\hline Decline in ability to have an erection over last year & 2,004 & $1.35(1.01,1.81)^{*}$ & $1.47(1.06,2.04)^{*}$ & $1.16(0.87,1.55)$ & $1.28(0.81,2.03)$ \\
\hline Increased concern about level of sexual desire & 2,002 & $1.71(1.31,1.23)^{* * *}$ & $1.62(1.21,2.18)^{* *}$ & $1.03(0.79,1.35)$ & $1.08(0.68,1.71)$ \\
\hline Increased concern about frequency of sexual activities & 2,002 & $1.45(1.10,1.89)^{* *}$ & $1.37(1.00,1.87)^{*}$ & $0.98(0.75,1.27)$ & $0.65(0.40,1.06)$ \\
\hline Increased concern about ability to have an erection & 2,004 & $1.29(1.00,1.65)^{*}$ & $1.34(1.02,1.78)^{*}$ & $0.96(0.74,1.23)$ & $0.78(0.49,1.25)$ \\
\hline Increased concern about ability to have an orgasm & 1,712 & $1.22(0.90,1.66)$ & $1.37(0.99,1.89)$ & $1.15(0.84,1.56)$ & $0.89(0.50,1.56)$ \\
\hline Increased concern about overall sex life & 1,982 & $1.43(1.12,1.83)^{* *}$ & $1.53(1.14,2.05)^{* *}$ & $0.96(0.74,1.23)$ & $0.96(0.60,1.52)$ \\
\hline \multicolumn{6}{|l|}{ Women } \\
\hline Increased frequency of thinking about sex & 1,787 & $1.09(0.85,1.41)$ & $0.88(0.69,1.13)$ & $0.88(0.71,1.08)$ & $1.10(0.72,1.70)$ \\
\hline Increased frequency of sexual intercourse & 1,766 & $0.87(0.68,1.12)$ & $0.76(0.60,0.96)^{*}$ & $0.90(0.72,1.12)$ & $0.91(0.61,1.37)$ \\
\hline Increased frequency of kissing, fondling and petting & 1,765 & $1.07(0.83,1.43)$ & $1.13(0.88,1.46)$ & $0.94(0.75,1.17)$ & $1.02(0.68,1.55)$ \\
\hline Increased frequency of masturbation & 1,758 & $1.13(0.82,1.54)$ & $1.12(0.82,1.52)$ & $1.06(0.81,1.39)$ & $0.69(0.41,1.14)$ \\
\hline Increased difficulty becoming sexually aroused & 1,403 & $1.31(1.01,1.70)^{*}$ & $1.41(1.06,1.88)^{*}$ & $0.87(0.68,1.12)$ & $1.05(0.68,1.63)$ \\
\hline Increased difficulty achieving orgasm & 1,344 & $1.17(0.87,1.57)$ & $1.07(0.79,1.43)$ & $0.87(0.67,1.13)$ & $0.92(0.57,1.51)$ \\
\hline Increased experience of pain during sexual activity & 1,383 & $1.41(1.03,1.94)^{*}$ & $1.67(1.21,2.31)^{* *}$ & $0.94(0.70,1.25)$ & $1.00(0.60,1.68)$ \\
\hline Increased experience of vaginal dryness during sexual activity & 1,382 & $1.29(0.95,1.76)$ & $1.69(1.24,2.30)^{* *}$ & $1.09(0.85,1.41)$ & $1.06(0.67,1.68)$ \\
\hline Decline in sexual drive over last year & 1,794 & $1.26(0.94,1.67)$ & $1.63(1.18,2.24)^{* *}$ & $1.06(0.81,1.38)$ & $0.81(0.49,1.36)$ \\
\hline
\end{tabular}


Decline in frequency of sexual activities over last year Decline in ability to become sexually aroused over last year Increased concern about level of sexual desire

Increased concern about frequency of sexual activities Increased concern about ability to become sexually aroused Increased concern about ability to have an orgasm

Increased concern about overall sex life

$\begin{array}{lllll}1,774 & 1.10(0.83,1.45) & 1.46(1.07,1.98)^{*} & 1.22(0.95,1.57) & 0.89(0.56,1.41) \\ 1,394 & 2.00(1.39,2.86)^{* * *} & 1.93(1.35,2.76)^{* * *} & 1.03(0.75,1.40) & 0.99(0.57,1.72) \\ 1,799 & 1.32(0.97,1.80) & 1.57(1.13,2.19)^{* *} & 0.82(0.63,1.08) & 0.94(0.54,1.65) \\ 1,774 & 1.53(1.10,2.13)^{*} & 1.48(1.05,2.09)^{*} & 0.98(0.73,1.32) & 1.03(0.54,1.96) \\ 1,395 & 1.48(1.05,2.09)^{*} & 1.56(1.08,2.25)^{*} & 1.02(0.74,1.40) & 1.31(0.68,2.51) \\ 1,335 & 1.17(0.79,1.74) & 1.65(1.08,2.53)^{*} & 0.96(0.67,1.39) & 0.78(0.37,1.62) \\ 1,734 & 1.75(1.31,2.34)^{* * *} & 1.82(1.34,2.48)^{* * *} & 1.12(0.86,1.45) & 1.16(0.66,2.05)\end{array}$

$* p<0.05 ; * * p<0.01 ; * * * p<0.001$

Weighted logistic regressions adjusted for age, partner status, age left education, self-rated health, depression, physical activity level, pain, smoking status and frequency of alcohol consumption

Note ${ }^{l}$ : The denominator varies due to questionnaire routing (see http://www.elsa-project.ac.uk) and some participants declining to answer certain questions

Note $^{2}$ : In the above models when 'self-rated health' was replaced by the 'morbidity count' variable no substantive changes in the magnitude of the reported odds ratios or statistical significance were observed (data not shown) 
Table $5 \mid$ Association of retrospective sleep quality with sexual health variables in men and women reporting 'any' sexual activity in the last 12 months. Multiple logistic regressions: weighted odds ratios ( $95 \%$ confidence intervals). Reference category $=$ No Restless Sleep reported.

\begin{tabular}{|c|c|c|c|}
\hline Sexual health variables & $\mathrm{n}$ & $\begin{array}{l}\text { Restless sleep reported at } \\
\text { one or two waves }\end{array}$ & $\begin{array}{l}\text { Restless sleep reported at } \\
\text { three waves or more }\end{array}$ \\
\hline \multicolumn{4}{|l|}{ Men } \\
\hline Increased frequency of thinking about sex & 1,733 & $1.34(0.99,1.72)$ & $1.23(0.92,1.75)$ \\
\hline Increased frequency of sexual intercourse & 1,721 & $0.93(0.75,1.15)$ & $0.86(0.67,1.11)$ \\
\hline Increased frequency of kissing, fondling and petting & 1,722 & $0.94(0.76,1.18)$ & $0.90(0.70,1.16)$ \\
\hline Increased frequency of masturbation & 1,722 & $1.18(0.95,1.47)$ & $1.37(1.05,1.77)^{*}$ \\
\hline Increased difficulty achieving an erection & 1,733 & $1.10(0.88,1.37)$ & $1.18(0.90,1.53)$ \\
\hline Increased difficulty achieving orgasm & 1,495 & $1.10(0.85,1.43)$ & $1.19(0.89,1.59)$ \\
\hline Decline in sexual drive over last year & 1,736 & $0.81(0.62,1.05)$ & $1.36(1.00,1.85)^{*}$ \\
\hline Decline in frequency of sexual activities over last year & 1,732 & $0.98(0.76,1.26)$ & $1.40(1.04,1.89)^{*}$ \\
\hline Decline in ability to have an erection over last year & 1,740 & $1.05(0.79,1.39)$ & $1.60(1.16,2.21)^{* *}$ \\
\hline Increased concern about level of sexual desire & 1,737 & $1.08(0.85,1.39)$ & $1.46(1.10,1.94)^{* *}$ \\
\hline Increased concern about frequency of sexual activities & 1,730 & $1.04(0.81,1.34)$ & $1.65(1.24,2.20)^{* * *}$ \\
\hline Increased concern about ability to have an erection & 1,741 & $1.14(0.90,1.43)$ & $1.58(1.19,2.11)^{* *}$ \\
\hline Increased concern about ability to have an orgasm & 1,471 & $1.28(0.98,1.69)$ & $1.75(1.28,2.39) * * *$ \\
\hline Increased concern about overall sex life & 1,718 & $1.30(1.03,1.64)^{*}$ & $1.94(1.47,2.57)^{* *}$ \\
\hline \multicolumn{4}{|l|}{ Women } \\
\hline Increased frequency of thinking about sex & 1,516 & $0.89(0.69,1.14)$ & $0.79(0.61,1.04)$ \\
\hline Increased frequency of sexual intercourse & 1,494 & $0.91(0.71,1.18)$ & $0.82(0.62,1.07)$ \\
\hline Increased frequency of kissing, fondling and petting & 1,494 & $1.03(0.79,1.33)$ & $0.89(0.68,1.17)$ \\
\hline Increased frequency of masturbation & 1,490 & $1.25(0.91,1.71)$ & $1.07(0.76,1.51)$ \\
\hline Increased difficulty becoming sexually aroused & 1,170 & $1.12(0.85,1.48)$ & $1.40(1.03,1.88)^{*}$ \\
\hline Increased difficulty achieving orgasm & 1,114 & $1.00(0.75,1.34)$ & $0.99(0.72,1.37)$ \\
\hline Increased experience of pain during sexual activity & 1,153 & $1.87(1.34,2.62)^{* * *}$ & $2.11(1.50,2.98)^{* * *}$ \\
\hline Increased experience of vaginal dryness during sexual activity & 1,152 & $1.45(1.08,1.94)^{*}$ & $1.50(1.10,2.05)^{* *}$ \\
\hline Decline in sexual drive over last year & 1,522 & $1.41(1.00,2.00)^{*}$ & $1.60(1.13,2.27)^{* *}$ \\
\hline Decline in frequency of sexual activities over last year & 1,502 & $1.11(0.81,1.52)$ & $1.48(1.07,2.04)^{*}$ \\
\hline Decline in ability to become sexually aroused over last year & 1,164 & $1.22(0.82,1.83)$ & $1.55(1.02,2.35)^{*}$ \\
\hline Increased concern about level of sexual desire & 1,526 & $1.10(0.77,1.57)$ & $1.53(1.06,2.20)^{*}$ \\
\hline Increased concern about frequency of sexual activities & 1,502 & $1.40(0.96,2.04)$ & $1.92(1.31,2.82)^{* *}$ \\
\hline Increased concern about ability to become sexually aroused & 1,163 & $1.45(0.99,2.13)$ & $1.68(1.13,2.49)^{*}$ \\
\hline Increased concern about ability to have an orgasm & 1,107 & $0.82(0.52,1.28)$ & $1.17(0.74,1.86)$ \\
\hline Increased concern about overall sex life & 1,472 & $1.25(0.90,1.74)$ & $1.78(1.27,2.48)^{* *}$ \\
\hline
\end{tabular}

${ }^{*} p<0.05 ; * * p<0.01 ; * * * p<0.001$

Weighted logistic regressions adjusted for age, partner status, age left education, self-rated health, depression, physical activity level, pain, smoking status and frequency of alcohol consumption

Note $^{I}$ : The denominator varies due to questionnaire routing (see http://www.elsa-project.ac.uk) and some participants declining to answer some questions

$N^{2} e^{2}$ : In the above models when 'self-rated health' was replaced by the 'morbidity count' variable no substantive changes in the magnitude of the reported odds ratios or statistical significance were observed (data not shown) 
Appendix 1 | Associations between sleep disturbance (ordered tertiles: minimal, moderate, high) and the covariates included in the multiple ordinal logistic regressions (Table 4).

Simple ordinal logistic regressions: sleep disturbance tertiles $=$ dependent variable.

\begin{tabular}{|c|c|c|}
\hline Adjustment variables & Men & Women \\
\hline & \multicolumn{2}{|c|}{ Odds ratios (95\% Confidence intervals) } \\
\hline Age (years) & $1.02(1.01,1.04)^{* * *}$ & $0.99(0.98,1.00)$ \\
\hline \multicolumn{3}{|l|}{ Partner status } \\
\hline Married/cohabiting & Reference & Reference \\
\hline Divorced/separated & $1.28(0.98,1.67)$ & $0.83(0.64,1.07)$ \\
\hline Never married & $1.05(0.76,1.45)$ & $1.00(0.66,1.07)$ \\
\hline Widowed & $1.32(0.91,1.91)$ & $0.87(0.62,1.22)$ \\
\hline \multicolumn{3}{|l|}{ Age left education (years) } \\
\hline$\leq 14$ & Reference & Reference \\
\hline 15-18 & $0.83(0.57,1.21)$ & $1.28(0.80,2.06)$ \\
\hline$\geq 19$ & $0.71(0.48,1.06)$ & $0.98(0.60,1.60)$ \\
\hline \multicolumn{3}{|l|}{ Self-rated health } \\
\hline Excellent/very good & Reference & Reference \\
\hline Good & $1.84(1.52,2.22)^{* * *}$ & $1.63(1.35,1.98)^{* * *}$ \\
\hline Fair/poor & $4.34(3.49,5.41)^{* * *}$ & $3.31(2.61,4.21)^{* * *}$ \\
\hline \multicolumn{3}{|l|}{ Diabetes $^{\mathrm{a}}$} \\
\hline No & Reference & Reference \\
\hline Yes & $1.12(0.87,1.44)$ & $1.29(0.90,1.83)$ \\
\hline \multicolumn{3}{|l|}{ Cardiovascular disease $^{a}$} \\
\hline No & Reference & Reference \\
\hline Yes & $1.41(1.11,1.78)^{* *}$ & $1.35(1.01,1.82)^{*}$ \\
\hline \multicolumn{3}{|l|}{ Depression $^{b}$} \\
\hline No & Reference & Reference \\
\hline Yes & $8.07(5.75,11.3)^{* * *}$ & $4.21(3.15,5.63)^{* * *}$ \\
\hline \multicolumn{3}{|l|}{ Physical activity level } \\
\hline Mod/vigorous PA $\geq$ once/week & Reference & Reference \\
\hline Mod/vigorous PA $<$ once/week & $1.54(1.22,1.95)^{* * *}$ & $1.48(1.17,1.88)^{* *}$ \\
\hline \multicolumn{3}{|l|}{ Pain } \\
\hline No pain & Reference & Reference \\
\hline Often troubled by pain & $3.03(2.55,3.60)^{* * *}$ & $2.61(2.19,3.10)^{* * *}$ \\
\hline \multicolumn{3}{|l|}{ Smoking status } \\
\hline Never/ex-smoker & Reference & Reference \\
\hline Current smoker & $1.15(0.89,1.49)$ & $1.00(0.76,1.31)$ \\
\hline \multicolumn{3}{|l|}{ Frequency of alcohol consumption ${ }^{c}$} \\
\hline Never/rarely & Reference & Reference \\
\hline Regularly & $0.60(0.52,0.70)^{* * *}$ & $0.87(0.71,1.07)$ \\
\hline Very frequently & $0.55(0.46,0.66)^{* * *}$ & $0.76(0.60,0.98)^{*}$ \\
\hline
\end{tabular}

$* p \leq 0.05, * * p \leq 0.01, * * * p \leq 0.001$

${ }^{a}$ Also includes self-reported use of medications to control/prevent these chronic conditions

${ }^{\mathrm{b}}$ CES-D (8-item) score of $\geq 4$

${ }^{c}$ Frequency of alcohol consumption over the past year (never/rarely $=$ never-once or twice, regularly $=$ once every 2 months-twice a week, very frequently $=3$ days a week-daily) 
Appendix 2 | Associations between sleep duration (ordered categories: short, average, long) and the covariates included in the multiple ordinal logistic regressions (Table 4).

Simple ordinal logistic regressions: sleep duration categories $=$ dependent variable.

\begin{tabular}{|c|c|c|}
\hline Adjustment variables & Men & Women \\
\hline & \multicolumn{2}{|c|}{ Odds ratios (95\% Confidence intervals) } \\
\hline Age (years) & $1.03(1.01,1.04)^{* * *}$ & $1.01(0.99,1.02)$ \\
\hline \multicolumn{3}{|l|}{ Partner status } \\
\hline Married/cohabiting & Reference & Reference \\
\hline Divorced/separated & $0.66(0.46,0.97)^{*}$ & $0.82(0.58,1.15)$ \\
\hline Never married & $0.77(0.49,1.20)$ & $1.18(0.66,2.11)$ \\
\hline Widowed & $0.81(0.47,1.39)$ & $0.88(0.55,1.40)$ \\
\hline \multicolumn{3}{|l|}{ Age left education (years) } \\
\hline$\leq 14$ & Reference & Reference \\
\hline 15-18 & $1.23(0.72,2.10)$ & $0.65(0.33,1.27)$ \\
\hline$\geq 19$ & $1.60(0.91,2.80)$ & $0.88(0.44,1.77)$ \\
\hline \multicolumn{3}{|l|}{ Self-rated health } \\
\hline Excellent/very good & Reference & Reference \\
\hline Good & $0.68(0.51,0.86)^{* *}$ & $0.73(0.56,0.95)^{*}$ \\
\hline Fair/poor & $0.38(0.28,0.51)^{* * *}$ & $0.56(0.41,0.77)^{* * *}$ \\
\hline \multicolumn{3}{|l|}{ Diabetes $^{\mathrm{a}}$} \\
\hline No & Reference & Reference \\
\hline Yes & $1.06(0.73,1.54)$ & $0.97(0.60,1.57)$ \\
\hline \multicolumn{3}{|l|}{ Cardiovascular disease $^{a}$} \\
\hline No & Reference & Reference \\
\hline Yes & $1.10(0.78,1.56)$ & $0.83(0.56,1.25)$ \\
\hline \multicolumn{3}{|l|}{ Depression $^{b}$} \\
\hline No & Reference & Reference \\
\hline Yes & $0.21(0.14,0.31)^{* * *}$ & $0.44(0.31,0.62)^{* * *}$ \\
\hline \multicolumn{3}{|l|}{ Physical activity level } \\
\hline Mod/vigorous PA $\geq$ once/week & Reference & Reference \\
\hline Mod/vigorous PA $<$ once/week & $0.58(0.42,0.81)^{* *}$ & $0.71(0.52,0.97)^{*}$ \\
\hline \multicolumn{3}{|l|}{ Pain } \\
\hline No pain & Reference & Reference \\
\hline Often troubled by pain & $0.42(0.33,0.54)^{* * *}$ & $0.52(0.41,0.66)^{* * *}$ \\
\hline \multicolumn{3}{|l|}{ Smoking status } \\
\hline Never/ex-smoker & Reference & Reference \\
\hline Current smoker & $0.52(0.37,0.74)^{* * *}$ & $0.69(0.48,0.99)^{*}$ \\
\hline \multicolumn{3}{|l|}{ Frequency of alcohol consumption ${ }^{\mathfrak{c}}$} \\
\hline Never/rarely & Reference & Reference \\
\hline Regularly & $1.66(1.20,2.32)^{* *}$ & $1.21(0.92,1.60)$ \\
\hline Very frequently & $1.89(1.30,2.73)^{* *}$ & $1.35(0.96,1.89)$ \\
\hline
\end{tabular}

${ }^{*} p \leq 0.05, * * p \leq 0.01, * * * p \leq 0.001$

${ }^{a}$ Also includes self-reported use of medications to control/prevent these chronic conditions

${ }^{\mathrm{b}}$ CES-D (8-item) score of $\geq 4$

${ }^{c}$ Frequency of alcohol consumption over the past year (never/rarely $=$ never-once or twice, regularly $=$ once every 2 months-twice a week, very frequently $=3$ days a week-daily) 
Appendix 3 | Associations between key sexual health variables (coded as in main analysis: see Table 1) and the covariates included in the multiple ordinal logistic regressions (Table 4).

Simple ordinal logistic regressions for $\underline{\text { men}}$ : sexual health variables $=$ dependent variables.

\begin{tabular}{|c|c|c|c|c|c|c|c|c|}
\hline Adjustment variables & $\begin{array}{l}\text { Frequency of } \\
\text { thinking } \\
\text { about sex }\end{array}$ & $\begin{array}{l}\text { Frequency of } \\
\text { sexual } \\
\text { intercourse }\end{array}$ & $\begin{array}{l}\text { Erectile } \\
\text { function }\end{array}$ & $\begin{array}{l}\text { Change in } \\
\text { sexual desire } \\
\text { in last year }\end{array}$ & $\begin{array}{l}\text { Change in } \\
\text { frequency of } \\
\text { sexual activity } \\
\text { in last year }\end{array}$ & $\begin{array}{l}\text { Change in } \\
\text { ability to have } \\
\text { an erection in } \\
\text { last year }\end{array}$ & $\begin{array}{l}\text { Worried } \\
\text { about level of } \\
\text { sexual desire }\end{array}$ & $\begin{array}{l}\text { Worried } \\
\text { about } \\
\text { frequency of } \\
\text { sexual activity }\end{array}$ \\
\hline & \multicolumn{8}{|c|}{ Odds ratios (standard error) } \\
\hline Age (years) & $0.92(0.01)^{* * *}$ & $0.95(0.01)^{* * *}$ & $1.11(0.01)^{* * *}$ & $1.03(0.01)^{* * *}$ & $1.01(0.01)^{*}$ & $1.06(0.01)^{* * *}$ & $1.02(0.01)^{* *}$ & $0.99(0.01)$ \\
\hline \multicolumn{9}{|l|}{ Partner status } \\
\hline Married/cohabiting & Reference & Reference & Reference & Reference & Reference & Reference & Reference & Reference \\
\hline Divorced/separated & $1.80(0.30)^{* * *}$ & $1.10(0.15)$ & $0.76(0.10)^{*}$ & $0.71(0.11)^{*}$ & $0.85(0.12)$ & $0.65(0.12)^{*}$ & $0.85(0.13)$ & $0.64(0.10)^{* *}$ \\
\hline Never married & $1.75(0.35)^{* *}$ & $0.35(0.06)^{* * *}$ & $0.87(0.13)$ & $0.75(0.14)$ & $0.61(0.11)^{* *}$ & $0.62(0.14)^{*}$ & $0.62(0.12)^{*}$ & $0.45(0.09)^{* * *}$ \\
\hline Widowed & $0.73(0.15)$ & $0.46(0.09)^{* * *}$ & $2.04(0.39)^{* * *}$ & $0.86(0.18)$ & $1.04(0.21)$ & $1.46(0.32)$ & $0.79(0.17)$ & $0.53(0.12)^{* *}$ \\
\hline \multicolumn{9}{|l|}{ Age left education (years) } \\
\hline$\leq 14$ & Reference & Reference & Reference & Reference & Reference & Reference & Reference & Reference \\
\hline$\overline{15-18}$ & $1.86(0.38)^{* *}$ & $1.06(0.20)$ & $0.33(0.06)^{* * *}$ & $0.44(0.09)^{* * *}$ & $0.67(0.14)$ & $0.50(0.10)^{* *}$ & $0.87(0.19)$ & $1.44(0.34)$ \\
\hline$\geq 19$ & $3.34(0.74)^{* * *}$ & $1.20(0.24)$ & $0.28(0.06)^{* * *}$ & $0.38(0.08)^{* * *}$ & $0.61(0.13)^{*}$ & $0.49(0.11)^{* *}$ & $1.08(0.24)$ & $2.20(0.53)^{* *}$ \\
\hline \multicolumn{9}{|l|}{ Self-rated health } \\
\hline Excellent/very good & Reference & Reference & Reference & Reference & Reference & Reference & Reference & Reference \\
\hline Good & $0.67(0.07)^{* * *}$ & $0.62(0.06)^{* * *}$ & $1.82(0.17)^{* * *}$ & $1.62(0.17)^{* * *}$ & $1.51(0.15)^{* * *}$ & $1.47(0.17)^{* *}$ & $1.47(0.15)^{* * *}$ & $1.25(0.13)^{*}$ \\
\hline Fair/poor & $0.51(0.06)^{* * *}$ & $0.44(0.05)^{* * *}$ & $2.74(0.29)^{* * *}$ & $1.86(0.22)^{* * *}$ & $1.84(0.21)^{* * *}$ & $2.00(0.26)^{* * *}$ & $1.82(0.21)^{* * *}$ & $1.61(0.19)^{* * *}$ \\
\hline \multicolumn{9}{|l|}{ Diabetes $^{\mathbf{a}}$} \\
\hline No & Reference & Reference & Reference & Reference & Reference & Reference & Reference & Reference \\
\hline Yes & $0.72(0.10)^{*}$ & $0.63(0.08)^{* * *}$ & $2.18(0.28)^{* * *}$ & $1.52(0.21)^{* *}$ & $1.14(0.16)$ & $1.62(0.24)^{* *}$ & $1.51(0.21)^{* *}$ & $1.28(0.18)$ \\
\hline \multicolumn{9}{|l|}{ Cardiovascular disease $^{a}$} \\
\hline No & Reference & Reference & Reference & Reference & Reference & Reference & Reference & Reference \\
\hline Yes & $0.64(0.08)^{* *}$ & $0.69(0.08)^{* *}$ & $2.05(0.24)^{* * *}$ & $1.61(0.21)^{* * *}$ & $1.38(0.18)^{*}$ & $1.55(0.22)^{* *}$ & $1.47(0.18)^{* *}$ & $1.28(0.17)$ \\
\hline \multicolumn{9}{|l|}{ Depression $^{b}$} \\
\hline No & Reference & Reference & Reference & Reference & Reference & Reference & Reference & Reference \\
\hline Yes & $1.07(0.18)$ & $0.64(0.10)^{* *}$ & $1.78(0.27)^{* * *}$ & $1.79(0.29)^{* * *}$ & $2.07(0.33)^{* * *}$ & $1.79(0.31)^{* *}$ & $1.98(0.31)^{* * *}$ & $2.13(0.36)^{* * *}$ \\
\hline \multicolumn{9}{|l|}{ Physical activity level } \\
\hline Mod/vig PA $\geq$ once/week & Reference & Reference & Reference & Reference & Reference & Reference & Reference & Reference \\
\hline Mod/vig PA < once/week & $0.66(0.08)^{* *}$ & $0.62(0.07)^{* * *}$ & $1.92(0.23)^{* * *}$ & $1.51(0.19)^{* *}$ & $1.43(0.18)^{* *}$ & $1.53(0.21)^{* *}$ & $1.21(0.16)$ & $1.06(0.14)$ \\
\hline \multicolumn{9}{|l|}{ Pain } \\
\hline No pain & Reference & Reference & Reference & Reference & Reference & Reference & Reference & Reference \\
\hline Often troubled by pain & $0.74(0.07)^{* *}$ & $0.74(0.06)^{* * *}$ & $1.53(0.13)^{* * *}$ & $1.68(0.16)^{* * *}$ & $1.63(0.15)^{* * *}$ & $1.49(0.15)^{* * *}$ & $1.43(0.13)^{* * *}$ & $1.64(0.15)^{* * *}$ \\
\hline
\end{tabular}


Smoking status

Never/ex-smoker

Reference

Reference

Current smoker

$0.94(0.13)$

$0.74(0.09)^{*}$

Reference

Reference

$1.18(0.16)$

Reference

Reference

Reference

Frequency of alcohol

\begin{tabular}{lll} 
Reference & Reference & Reference \\
$1.89(0.23)^{* * *}$ & $1.63(0.19)^{* * *}$ & $0.75(0.09)^{*}$ \\
\hline
\end{tabular}

Reference

Reference

$0.97(0.13)$

$0.95(0.14)$

consumption ${ }^{c}$

Never/rarely
Regularly

$0.96(0.13)$

$1.05(0.13)$

Reference

Reference

Reference

Very frequently

$2.27(0.32)^{* * *} \quad 1.63(0.21)^{* * *} \quad 1.78(0.10) \quad 0.88(0.13)$

$1.84(0.21)$

$1.11(0.18)$

$1.11(0.15)$

$1.26(0.17)$

$* p \leq 0.05, * * p \leq 0.01, * * * p \leq 0.001$

${ }^{a}$ Also includes self-reported use of medications to control/prevent these chronic conditions

${ }^{b}$ CES-D (8-item) score of $\geq 4$

${ }^{c}$ Frequency of alcohol consumption over the past year (never/rarely $=$ never-once or twice, regularly $=$ once every 2 months-twice a week, very frequently $=3$ days a weekdaily) 
Appendix 4 | Associations between key sexual health variables (coded as in main analysis: see Table 1) and the covariates included in the multiple ordinal logistic regressions (Table 4).

Simple ordinal logistic regressions for women: sexual health variables $=$ dependent variables.

\begin{tabular}{|c|c|c|c|c|c|c|c|c|}
\hline Adjustment variables & $\begin{array}{l}\text { Frequency of } \\
\text { thinking } \\
\text { about sex }\end{array}$ & $\begin{array}{l}\text { Frequency of } \\
\text { sexual } \\
\text { intercourse }\end{array}$ & Sexual arousal & $\begin{array}{l}\text { Change in } \\
\text { sexual desire } \\
\text { in last year }\end{array}$ & $\begin{array}{l}\text { Change in } \\
\text { frequency of } \\
\text { sexual activity } \\
\text { in last year }\end{array}$ & $\begin{array}{l}\text { Change in } \\
\text { sexual arousal } \\
\text { in last year }\end{array}$ & $\begin{array}{l}\text { Worried } \\
\text { about level of } \\
\text { sexual desire }\end{array}$ & $\begin{array}{l}\text { Worried } \\
\text { about } \\
\text { frequency of } \\
\text { sexual activity }\end{array}$ \\
\hline & \multicolumn{8}{|c|}{ Odds ratios (standard error) } \\
\hline Age (years) & $0.94(0.01)^{* * *}$ & $0.95(0.01)^{* * *}$ & $1.05(0.01)^{* * *}$ & $1.00(0.01)$ & $1.01(0.01)$ & $1.00(0.01)$ & $0.96(0.01)^{* * *}$ & $0.94(0.01)^{* * *}$ \\
\hline \multicolumn{9}{|l|}{ Partner status } \\
\hline Married/cohabiting & Reference & Reference & Reference & Reference & Reference & Reference & Reference & Reference \\
\hline Divorced/separated & $1.83(0.23)^{* * *}$ & $0.83(0.11)$ & $0.66(0.09)^{* *}$ & $0.83(0.12)$ & $0.87(0.12)$ & $0.87(0.16)$ & $0.68(0.11)^{*}$ & $0.69(0.12)^{*}$ \\
\hline Never married & $1.37(0.29)$ & $0.46(0.11)^{* *}$ & $0.53(0.13)^{* *}$ & $0.35(0.11)^{* *}$ & $0.53(0.13)^{*}$ & $0.62(0.20)$ & $0.68(0.18)$ & $0.63(0.19)$ \\
\hline Widowed & $0.85(0.15)$ & $0.53(0.10)^{* * *}$ & $0.71(0.15)$ & $0.69(0.14)$ & $0.73(0.14)$ & $0.61(0.17)$ & $0.38(0.10)^{* * *}$ & $0.42(0.12)^{* *}$ \\
\hline \multicolumn{9}{|l|}{ Age left education (years) } \\
\hline$\leq 14$ & Reference & Reference & Reference & Reference & Reference & Reference & Reference & Reference \\
\hline $15-18$ & $2.15(0.51)^{* *}$ & $1.39(0.33)$ & $1.14(0.32)$ & $0.85(0.22)$ & $0.88(0.23)$ & $0.98(0.34)$ & $0.93(0.26)$ & $1.35(0.47)$ \\
\hline$\geq 19$ & $3.48(0.86)^{* * *}$ & $1.48(0.37)$ & $0.95(0.28)$ & $0.64(0.18)$ & $0.62(0.17)$ & $0.83(0.30)$ & $1.42(0.41)$ & $2.13(0.77)^{*}$ \\
\hline \multicolumn{9}{|l|}{ Self-rated health } \\
\hline Excellent/very good & Reference & Reference & Reference & Reference & Reference & Reference & Reference & Reference \\
\hline Good & $0.84(0.08)$ & $0.85(0.08)$ & $1.42(0.15)^{* *}$ & $1.33(0.15)^{* *}$ & $1.21(0.13)$ & $1.33(0.18)^{*}$ & $0.99(0.11)$ & $1.02(0.13)$ \\
\hline \multirow{2}{*}{\multicolumn{9}{|c|}{ Diabetes $^{\mathrm{a}}$}} \\
\hline & & & & & & & & \\
\hline No & Reference & Reference & Reference & Reference & Reference & Reference & Reference & Reference \\
\hline Yes & $0.89(0.16)$ & $0.65(0.11)^{*}$ & $1.21(0.25)$ & $1.20(0.24)$ & $1.45(0.28)^{*}$ & $1.40(0.36)$ & $0.69(0.16)$ & $0.81(0.20)$ \\
\hline \multicolumn{9}{|l|}{ Cardiovascular disease $^{\mathrm{a}}$} \\
\hline No & Reference & Reference & Reference & Reference & Reference & Reference & Reference & Reference \\
\hline Yes & $0.64(0.10)^{* *}$ & $0.72(0.11)^{*}$ & $1.31(0.23)$ & $1.10(0.18)$ & $1.40(0.23)^{*}$ & $1.28(0.27)$ & $0.71(0.14)$ & $0.86(0.17)$ \\
\hline \multicolumn{9}{|l|}{ Depression $^{b}$} \\
\hline No & Reference & Reference & Reference & Reference & Reference & Reference & Reference & Reference \\
\hline Yes & $0.95(0.13)$ & $0.60(0.08)^{* * *}$ & $1.64(0.26)^{* *}$ & $1.67(0.24) * * *$ & $1.89(0.28)^{* * *}$ & $1.57(0.29)^{*}$ & $1.63(0.24)^{* *}$ & $1.83(0.29)^{* * *}$ \\
\hline \multicolumn{9}{|l|}{ Physical activity level } \\
\hline Mod/vig PA $\geq$ once/week & Reference & Reference & Reference & Reference & Reference & Reference & Reference & Reference \\
\hline Mod/vig PA < once/week & $0.63(0.07)^{* * *}$ & $0.72(0.09)^{* *}$ & $1.30(0.17)^{*}$ & $1.11(0.15)$ & $1.11(0.14)$ & $1.08(0.18)$ & $0.81(0.12)$ & $0.79(0.13)$ \\
\hline \multicolumn{9}{|l|}{ Pain } \\
\hline No pain & Reference & Reference & Reference & Reference & Reference & Reference & Reference & Reference \\
\hline Often troubled by pain & $0.98(0.08)$ & $0.84(0.07)^{*}$ & $1.19(0.11)$ & $1.24(0.12)^{*}$ & $1.27(0.12)^{*}$ & $1.01(0.12)$ & $1.21(0.12)$ & $1.35(0.15)^{* *}$ \\
\hline
\end{tabular}


Smoking status

Never/ex-smoke

Current smoker

$0.85(0.1$

Reference

Reference

Reference

Reference

Reference

Reference

Reference

Frequency of alcohol

$1.09(0.15)$

$1.20(0.18)$

$1.03(0.16)$

$0.82(0.13)$

$1.23(0.23)$

1.02 (0.17)

$0.88(0.16)$

consumption $^{\mathrm{c}}$

Never/rarely

Reference

Reference Reference

Reference

Reference

Reference

Reference

Reference

Very frequently

$\begin{array}{lll}1.62(0.16)^{* * *} & 1.33(0.13)^{* *} & 0.81(0.09) \\ 1.84(0.23)^{* * *} & 1.40(0.17)^{* *} & 0.96(0.13)\end{array}$

$0.79(0.09)^{*}$

$0.76(0.08)^{*}$

$0.76(0.11)$

$1.10(0.14)$

$1.03(0.14)$

${ }^{*} p \leq 0.05, * * p \leq 0.01, * * * p \leq 0.001$

${ }^{a}$ Also includes self-reported use of medications to control/prevent these chronic conditions

${ }^{b}$ CES-D (8-item) score of $\geq 4$

${ }^{c}$ Frequency of alcohol consumption over the past year (never/rarely $=$ never-once or twice, regularly $=$ once every 2 months-twice a week, very frequently $=3$ days a weekdaily) 